\title{
Reliability Analysis of Converters
}

\author{
Renita Pinto ${ }^{1}$, Bharathi A Rao ${ }^{2}$ \\ PG Student, E\&E Department, SJEC Vamanjoor, Mangaluru, India ${ }^{1}$ \\ Assistant Professor, E\&E Department, SJEC Vamanjoor, Mangaluru, India ${ }^{2}$
}

\begin{abstract}
Performance of power electronic converters has become a major concern in the present day. Converters should be designed with the objective of gaining a high efficiency, increased reliability and less complexity. This paper presents the reliability analysis of three converters. Reliability of two-stage Interleaved boost converter, two-stage and single-stage PFC converter is measured. It is shown that number of components in a device effects the reliability of a system.
\end{abstract}

Keywords: Reliability. MTBF, Power factor correction.

\section{INTRODUCTION}

Reliability has become the first priority in the design of a power system. A design is considered successful only if the system is cost effective, efficient and has a greater life time. Reliability of power system is one of the more focused topics today. A power converter consists of a collection of electronic components. None of the elements are perfect, and can fail as time passes and affect the operation of a system. Reliability is the measure of explaining how often these failures occur. In big industries, the lifetime of a system, the failure rates of each component and the overall cost is computed to explain how reliable a system is.It will not be good choice to implement a system practically, if a system is technically acceptable but has less reliability. Large number of components, internal and external stresses, types of the component, quality of the component affects the overall reliability of a system.

This paper presents the reliability analysis of three converters. Two-stage interleaved boost converter, single-stage flyback PFC converter and two-stage Boost-forward converter are designed and simulated using Orcad software. Failure rates of each component in the system are computed. The overall reliability of a system is calculated and the three converters are compared in terms of reliability. It is shown that, system with less number of components has a greater lifetime when compared to those with more number of components.

\section{CIRCUIT TOPOLOGIES}

Two-stage interleaved boost converter [5] is suitable for renewable sources of energy. For proper operation of a twostage interleaved boost converter, the gating signals given to two MOSFET's should be phase shifted by $180^{\circ}$. The current from the supply is divided between two branches. The input current ripples are minimum for a duty ratio of 0.5 [1].Circuit of a interleaved boost converter is shown in figure 1. Boost-forward converter [6] has two stages: boost converter on the input side and a forward converter on the output side. A turn's ratio of 0.5 is chosen to minimise the stresses.

A single stage flyback converter [6] works similar to that of a ordinary flyback converter. The only difference is that, in this converter if the voltage on the primary winding exceeds the power supply voltage then the diode D1 and D2 will return the excess energy back to the power supply. A turn's ratio of 0.5 is chosen to minimise the stresses on the switches [2]. This two switch flyback converter has a high efficiency and wide operating range [3]. An easy way to comply with the conference paper formatting requirements is to use this document as a template and simply type your text into it.

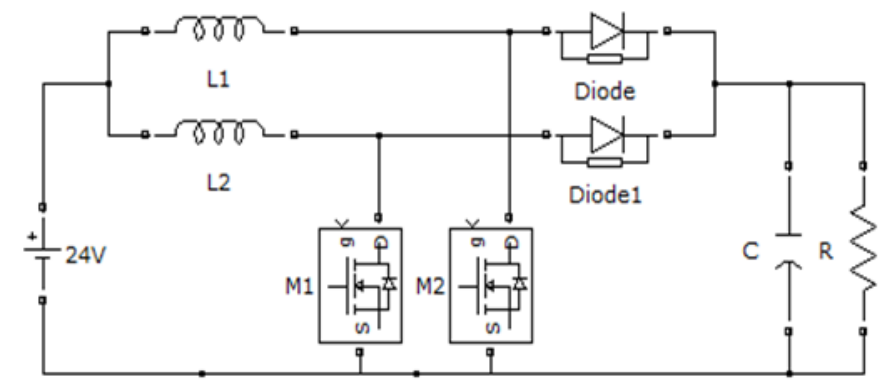

Fig 1: Two-stage Interleaved boost converter 
NMAM Institute of Technology, Nitte

Vol. 3, Special Issue 2, Month 2016

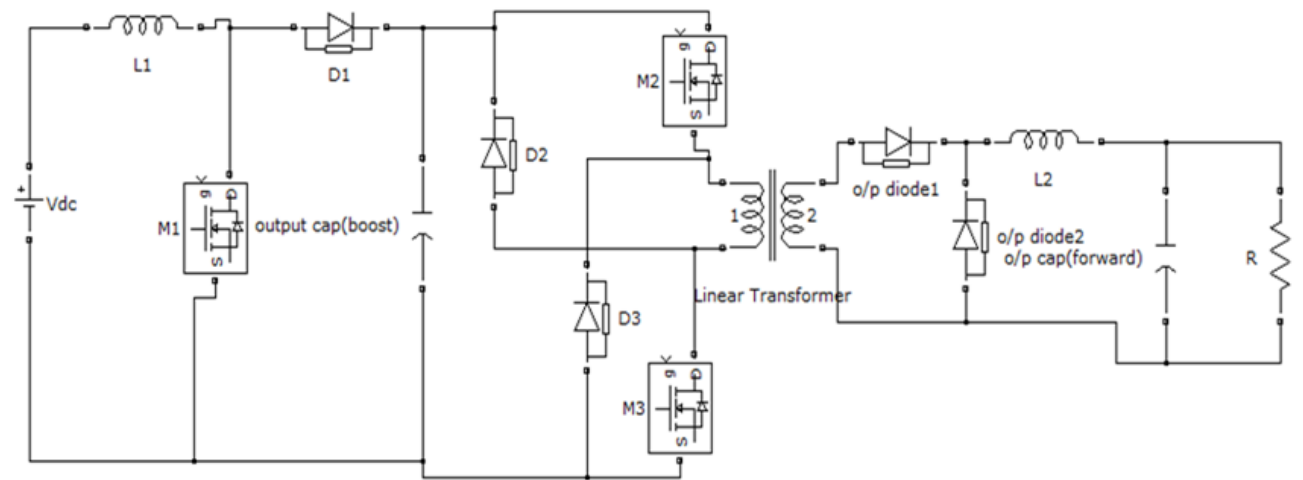

Fig 2: Two-stage Boost forward converter

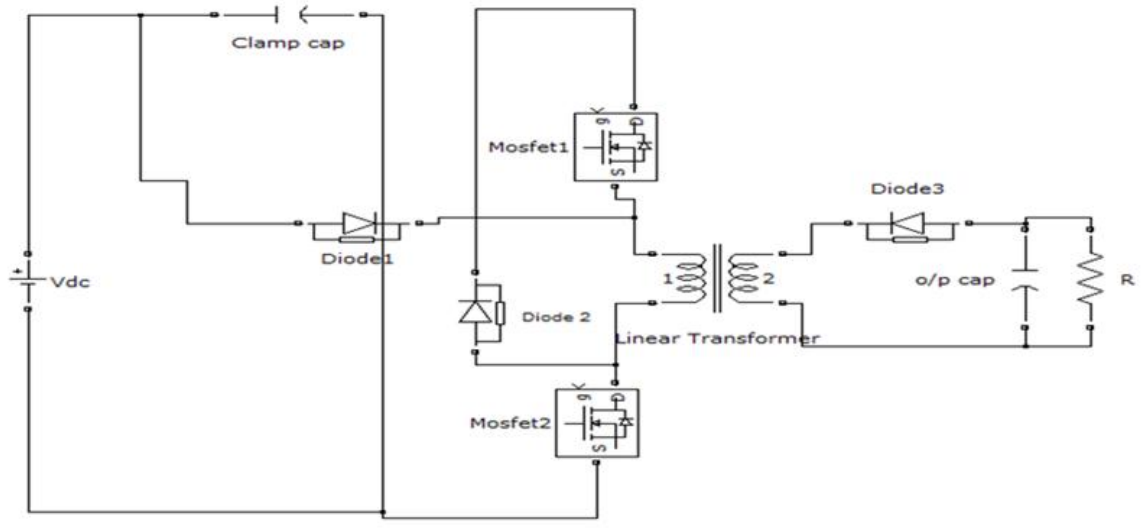

Fig 3: Single stage flyback converter

III. SIMULATION RESULTS

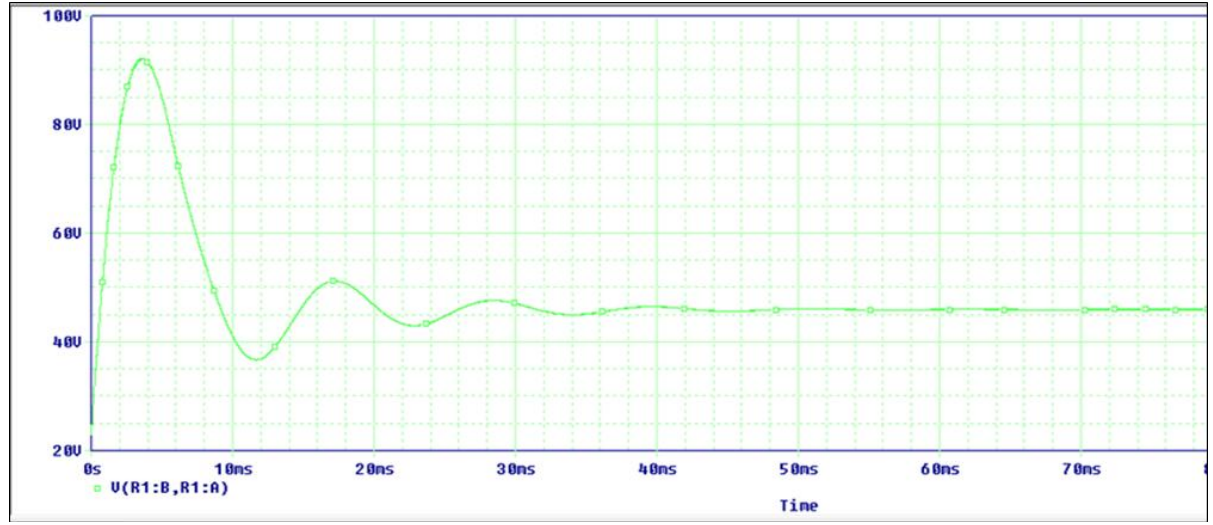

Fig 4: Output voltage of Interleaved boost converter

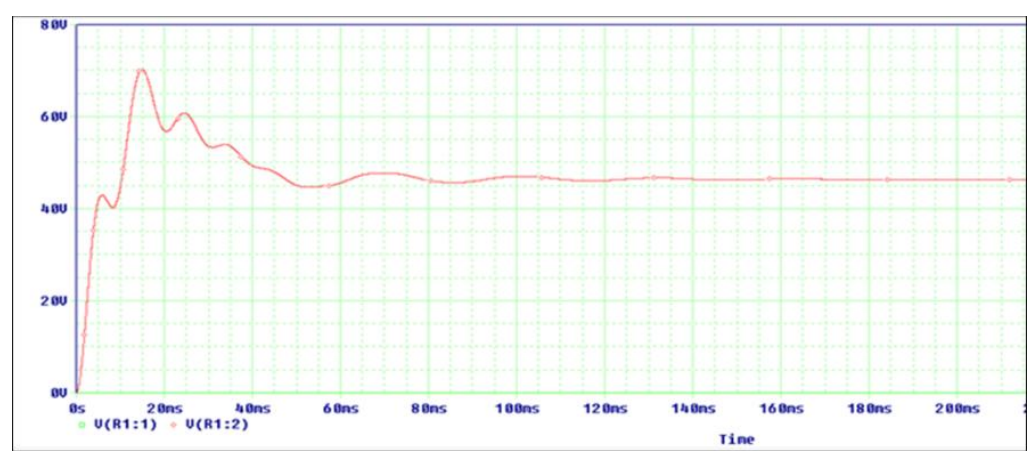

Fig 5: Output voltage of Two-stage boost-forward PFC converter 


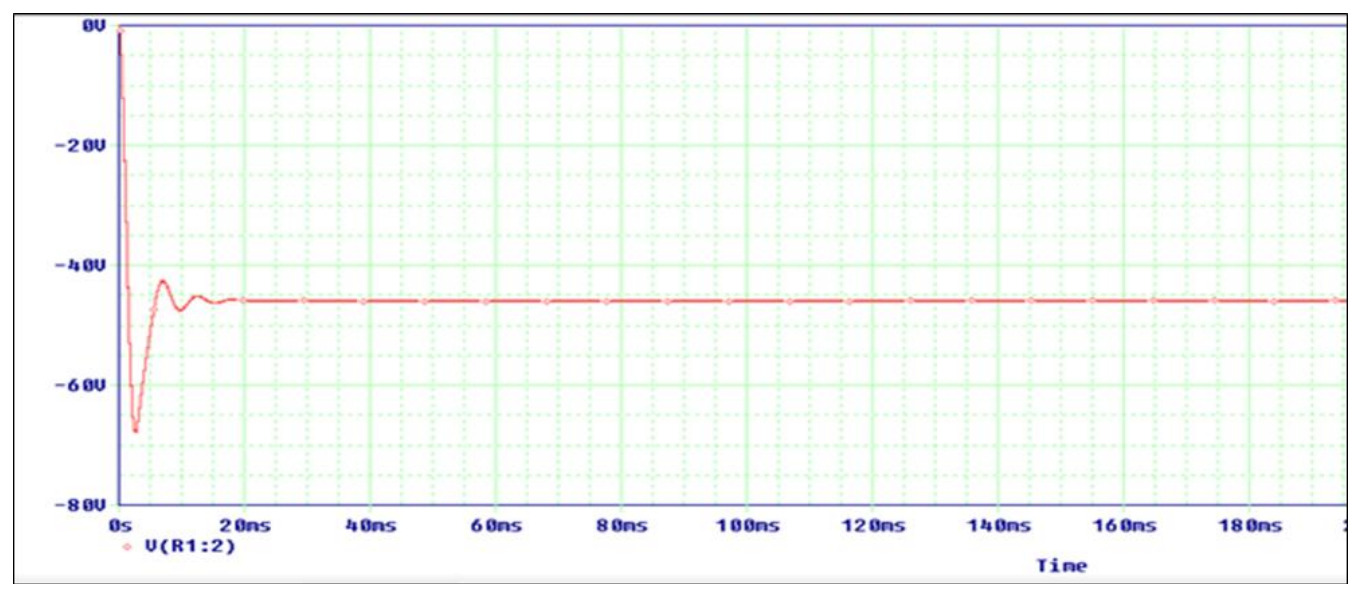

Fig 6: Output voltage of single-stage flyback converter

The circuits were designed for a output voltage of $48 \mathrm{~V}$ (nominal) and $350 \mathrm{~W}$ power (nominal). Circuits were designed using Orcad software. Output voltage of $47 \mathrm{~V}$ was obtained in all the three cases. Using the data obtained from the simulation failure rate was calculated for each component.

\section{RELIABILITY CALCULATIONS}

The mean time between failures MTBF is expressed as the reciprocal of the failure rate $\lambda . \lambda$ is calculated by following the procedure given in MIL-HDBK 217 [4]. The failure rate $\lambda_{\mathrm{b}}$ for various electronic devices is listed in this handbook. In order to calculate the reliability of any system, this failure rate $\lambda_{b}$ must be multiplied by the $\pi$ factors that define the stresses that a device undergoes. The total failure rate of a system is the sum of the failure rate of all the individual components in the system. The reliability of the overall system is then expressed as the reciprocal of the overall failure rate of the system. Table 1 shows the equations to calculate reliability as expressed in MIL-HDBK 217.

MOSFET undergoes four types of stresses; related to application (switching, linear, power etc.), temperature, quality (low, high) and environment (aerospace, military, ground fixed, laboratory etc.). Capacitor includes stresses related to capacitance value, operational environment, quality of the capacitor, temperature and votage rating.

TABLE 1: MODELS OF RELIABILITY

\begin{tabular}{|l|l|}
\hline Device & Models \\
\hline MOSFET & $\lambda_{\mathrm{p}}=\lambda_{\mathrm{b}}{ }^{*} \pi_{\mathrm{A}}{ }^{*} \pi_{\mathrm{T}} * \pi_{\mathrm{Q}}{ }^{*} \pi_{\mathrm{E}}$ \\
\hline Diode & $\lambda_{\mathrm{p}}=\lambda_{\mathrm{b}}{ }^{*} \pi_{\mathrm{S}}{ }^{*} \pi_{\mathrm{T}}{ }^{*} \pi_{\mathrm{C}}{ }^{*} \pi_{\mathrm{Q}}{ }^{*} \pi_{\mathrm{E}}$ \\
\hline Inductor & $\lambda_{\mathrm{p}}=\lambda_{\mathrm{b}}{ }^{*} \pi_{\mathrm{Q}}{ }^{*} \pi_{\mathrm{E}}$ \\
\hline Resistor & $\lambda_{\mathrm{p}}=\lambda_{\mathrm{b}}{ }^{*} \pi_{\mathrm{R}}{ }^{*} \pi_{\mathrm{Q}}{ }^{*} \pi_{\mathrm{E}}$ \\
\hline Capacitor & $\lambda_{\mathrm{p}}=\lambda_{\mathrm{b}}{ }^{*} \pi_{\mathrm{CV}}{ }^{*} \pi_{\mathrm{Q}}{ }^{*} \pi_{\mathrm{E}}$ \\
\hline Transformer & $\lambda_{\mathrm{p}}=\lambda_{\mathrm{b}}{ }^{*} \pi_{\mathrm{C}}{ }^{*} \pi_{\mathrm{Q}}{ }^{*} \pi_{\mathrm{E}}$ \\
\hline
\end{tabular}

Once the component type, value and the quality is known failure rate can be easily calculated by referring the MILHDBK 217. Ambient temperature of $27^{\circ} \mathrm{C}$ is considered. To calculate the reliability of a device, first the static and dynamic power losses of semiconductors should be considered. Following data is obtained by calculating the failure rate.

TABLE 2: RESULTS FROM RELIABILITY CLCULATIONS

\begin{tabular}{|c|c|c|c|}
\hline & $\begin{array}{c}\text { Interleaved } \\
\text { boost }\end{array}$ & $\begin{array}{c}\text { Boost- } \\
\text { Forward }\end{array}$ & $\begin{array}{c}\text { Single-stage } \\
\text { Flyback }\end{array}$ \\
\hline $\begin{array}{c}\text { Number of } \\
\text { components }\end{array}$ & 8 & 14 & 9 \\
\hline $\begin{array}{c}\text { Failure rate } \boldsymbol{\lambda}_{\text {sstem }} \\
\text { (failure/10 }\end{array}$ & 7.68702 & 21.22078 & 14.83794 \\
\hline MTBF $=\frac{\mathbf{1}}{\lambda}$ hours & $1,30,089$ & 47,123 & 67,394 \\
\hline
\end{tabular}


NMAM Institute of Technology, Nitte

Vol. 3, Special Issue 2, Month 2016

\section{CONCLUSION}

In this paper, reliability of two-stage interleaved boost converter, Single-stage flyback converter and two-stage boost forward PFC converter is calculated. The reliability calculations are done by referring the MIL-HDBK 217. From table 2 , we can conclude that as the number of components decreases, reliability of a system increases.

\section{ACKNOWLEDGMENT}

I thank my guide Mrs.Bharathi A Rao for her guidance and moral support. I also wish to thank the head of the department and the staff members of Electrical and Electronics Department, St. Joseph engineeringCollege for their valuable feedback.

\section{REFERENCES}

[1]. Mounica Ganta, Pallamreddy Nirupa, Thimmadi Akshitha, R.Seyezhai "Design and simulation of pwm fed two-phase interleaved boost converter for renewable energy source", International Journal of Electrical, Electronics and Data communication , ISSN: 2320-2084, march 2013

[2]. Gowrishankara C.K., GauravYadav, Chandan S "Design, Simulation and Implementation of Flyback based, True Single Stage, Isolated, Power Factor Corrected AC-DC Converter for Solar Array Simulators", International Journal of modern engineering Research, ISSN: 2249-6645, SepOct 2013

[3]. Marn-Go Kim and Young-Seok Jung, "A Novel Soft-Switching Two-Switch Flyback Converter with a Wide Operating Range and Regenerative Clamping”, Journal of Power Electronics, Vol 9, Sep 2009, JPE 9-5-11

[4]. MIL-HDBK 217

[5]. Hugo Calleja, Freddy Chan and Israel Uribe, "Reliability-Oriented Assessment of a DC/DC Converter for Photovoltaic Applications", IEEE Annual Power Electronics Specialists conference, July 2007

[6]. Amir Hossein Ranjbar, BabakAbdi, Gevork B. Gharehpetian, Babak Fahimi, "Reliability Assessment of Single-Stage/Two-Stage PFC converters", IEEE Power Electronics Controllers for power Systems, 2009 